\title{
Edukasi Pijat Laktasi pada Ibu Hamil Trimester III di Wilayah Kerja Puskesmas Jekan Raya Kota Palangka Raya
}

\section{Lactation Massage Education for Third Trimester Pregnant Women in the Work Area of the Jekan Raya Community Health Center, Palangka Raya}

Cia Aprilianti
Department of Applied Midwifery,
Poltekkes Kemenkes Palangka Raya,
Palangka Raya, Central Kalimantan,
Indonesia
*email: aprilianticia@poltekkes-
palangkaraya.ac.id
Kata Kunci
Edukasi
Ibu hamil
Pijat laktasi
Keywords:
Education
Pregnant mother
Lactation massage
Received: February 2020
Accepted: June 2020
Published: September 2020

\begin{abstract}
Abstrak
Gagalnya pelaksanaan Air Susu Ibu (ASI) Eksklusif sering kali didapatkan pada periode awal setelah persalinan karena ASI belum keluar menjadi alasan ibu untuk memberikan susu formula. Kegiatan ini bertujuan memberikan edukasi pijat laktasi pada ibu hamil trimester III untuk meningkatkan pengeluaran ASI. Kegiatan dilakukan sebanyak empat kali pertemuan. Pelaksanaan kegiatan berjalan dengan baik dan mayoritas karakteristik peserta seperti usia ibu yaitu ideal $(80 \%)$, paritas multi (70\%), ibu dengan tingkat pendidikan rendah (70\%), dan ibu bekerja sebagai IRT (90\%). Diharapkan kegiatan penyuluhan tentang pijat laktasi pada ibu hamil dapat dijadikan sebagai program rutin dari puskesmas dan petugas kesehatan, agar dapat mendampingi dan menyiapkan ibu hamil dengan pengetahuan tentang ASI Eksklusif menjelang persalinan.
\end{abstract}

\begin{abstract}
The failure to implement Exclusive Breast Milk (ASI) is often obtained in the early period after delivery because the milk has not yet been released is a reason for mothers to provide formula milk. This activity aims to provide lactation massage education for third-trimester pregnant women to increase breastfeeding. The activity was carried out in four meetings. The implementation of the activity went well, and the majority of participant characteristics were ideal $(80 \%)$, multi-parity $(70 \%)$, mothers with low education levels (70\%), and mothers working as IRT (90\%). It is hoped that outreach activities on lactation massage for pregnant women can be used as a routine program for health centers and health workers so that they can assist and prepare pregnant women with knowledge about exclusive breastfeeding before delivery.
\end{abstract}

(C) 2020 Cia Aprilianti. Published by Institute for Research and Community Services Universitas Muhammadiyah Palangkaraya. This is Open Access article under the CC-BY-SA License (http://creativecommons.org/licenses/by-sa/4.0/). DOI: https:// doi.org/10.33084/pengabdianmu.v5i4.1255

\section{PENDAHULUAN}

Pemberian ASI eksklusif hingga usia enam bulan masih rendah, sehingga sasaran program perbaikan gizi masyarakat untuk meningkatkan ASI eksklusif menjadi 80\% tampak terlalu tinggi (Fajar et al., 2018). Profil kesehatan Indonesia tahun 2016 menunjukkan cakupan bayi mendapatkan ASI Eksklusif hanya sebesar 29,5\% (Kementerian Kesehatan Republik Indonesia, 2017). Cakupan pemberian ASI Ekslusif di Provinsi Kalimantan Tengah rata-rata pada bayi sebesar 20,5\%, khususnya di Kota Palangka Raya sebesar 15,0\% (Dinas Kesehatan Kalimantan Tengah, 2017).

Manfaat pemberian ASI Eksklusif menurut berbagai penelitian telah dapat menurunkan mortalitas dan morbiditas bayi, pertumbuhan bayi yang optimal, perkembangan kecerdasan anak lebih baik, dan dapat membantu memperpanjang jarak kehamilan ibu (Ariestanti \& Widayati, 2018; Fikawati \& Syafiq, 2010). Gagalnya pelaksanaan ASI Eksklusif sering kali didapatkan pada periode awal setelah persalinan karena ASI belum keluar menjadi alasan ibu untuk memberikan 
susu formula (Oktafirnanda et al., 2019). Pemberian makanan/minuman pralakteal merupakan pemberian makanan/minuman pada bayi baru lahir sebelum ASI keluar (mendahului pemberian ASI), dilakukan dalam 3 hari pertama (Aditya et al., 2015).

Onset laktasi terlambat menyebabkan peluang lebih kecil dalam pemberikan ASI Eksklusif selama enam bulan (Aprilianti, 2018). Onset laktasi merupakan masa permulaan untuk memperbanyak air susu dimulai dari air susu keluar pertama kali ditandai payudara terasa keras, berat, bengkak sampai air susu atau kolostrum keluar (Septiani et al., 2018). Dikatakan onset laktasi cepat jika ASI keluar $\leq 72$ jam. Faktor risiko yang mempengaruhi onset laktasi yaitu usia, paritas, jenis persalinan, berat badan lahir, inisiasi menyusu dini, kecemasan, pijat oksitosin, dan status gizi (NommsenRivers et al., 2010). Umumnya, ASI keluar pada hari ke-2 atau ke-3 setalah persalinan. Upaya yang dilakukan agar mempercepat keluarnya ASI yaitu mempercepat onset laktasi dengan cara melakukan pijat pada ibu postpatum (Dewi \& Aprilianti, 2018).

Beberapa jenis pijat dapat dilakukan untuk membantu proses laktasi yaitu pijat laktasi dan pijat oksitosin. Pijat laktasi merupakan pemijatan dilakukan pada beberapa bagian tubuh, yaitu kepala, leher, bahu, punggung, dan payudara. Sedangkan pijat oksitosin, dilakukan pemijatan tulang belakang pada daerah punggung. Pada prinsipnya, kedua pijat ini dapat menimbulkan efek relaksasi untuk meningkatkan hormon oksitosin yang berperan meningkatkan hormon pengeluar ASI (Saudia, 2019). Adapun tujuan dari kegiatan ini untuk memberikan edukasi pijat laktasi pada ibu hamil trimester III.

\section{METODOLOGI}

Peserta kegiatan adalah ibu hamil dan keluarga yang bertempat tinggal di wilayah kerja Puskesmas Jekan
Raya sebanyak 10 orang. Kegiatan ini dilakukan sebanyak empat kali pertemuan. Pertemuan I merupakan kegiatan diskusi untuk mencari tahu sejauh mana pengetahuan/pemahaman dan memberikan informasi kepada ibu dan keluarga tentang pijat laktasi. Pertemuan II merupakan kegiatan mendampingi ibu hamil dan keluarga melakukan pijat laktasi. Pertemuan III dilakukan untuk mengetahui apakah ibu hamil dan keluarga sudah menerapkan pijat laktasi, serta menanyakan apakah ada efektivitas setelah dilakukan pijat laktasi. Selanjutnya, pertemuan IV merupakan evaluasi dari pertemuan I s.d III ditambah dengan memberikan layanan konseling. Media yang digunakan dalam kegiatan adalah leaflet untuk mempermudah peserta memahami kegiatan.

\section{HASIL DAN PEMBAHASAN}

Pelaksanaan kegiatan pengabdian kepada masyarakat ini adalah memberikan edukasi dan melatih melakukan pijat laktasi. Kegiatan ini berjalan dengan baik, terlihat dari antusias ibu hamil dan keluarga mengikuti serangkaian kegiatan dan mengajukan pertanyaan terkait pijat laktasi untuk meningkatkan pengeluaran ASI. Proses praktek pijat laktasi disajikan pada Gambar 1.

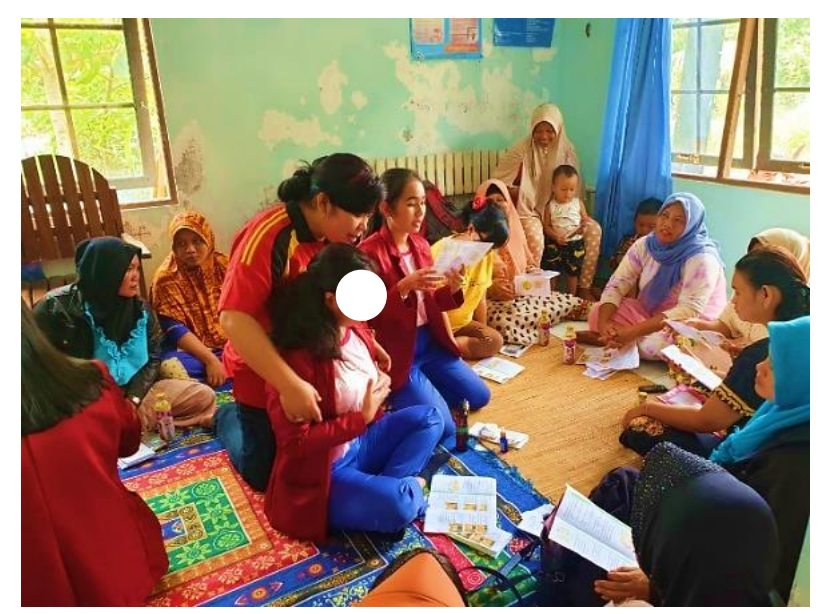

Gambar 1. Praktek Pijat Laktasi 
Pijat laktasi adalah gerakan pemijatan pada bagianbagian tubuh tertentu seperti kepala, leher, bahu, punggung, dan payudara untuk memperlancar proses menyusui. Jaringan payudara banyak berisi pembuluh getah bening dan pembuluh darah, pembuluh yang terhambat menjadi penyebab kurang lancarnya produksi dan aliran ASI (Aprilianti, 2018). Menghindari hal inilah ibu hamil dan menyusui dianjurkan untuk melakukan pijat laktasi. Prinsip pemijatan sama seperti pemijatan relaksasi pada umumnya. Untuk meningkatkan produksi ASI, maka diberikan penekanan pada titik-titik tertentu sambil mengusahakan ibu rileks sehingga merangsang produksi ASI yang sebelumnya belum ada menjadi ada, atau yang sebelumnya mendapat hambatan menjadi lancar. Pijat laktasi membersihkan saluran dan merangsang produksi ASI, dengan begitu saluran ASI menjadi lebih lancar, lamanya 30 menit hingga 1 jam sesuai dengan kebutuhan ibu (Dewi \& Aprilianti, 2018). Penyuluhan kesehatan tentang pijat laktasi merupakan hal mendasar dalam upaya mencapai peningkatan kesehatan ibu dan anak. Karakteristik peserta yang mengikuti kegiatan pengabdian kepada masyarakat yang terdiri dari 10 orang ibu hamil TM III disajikan pada Tabel I.

Tabel I. Karakteristik Peserta

\begin{tabular}{lcc}
\hline Karakteristik Peserta & n (10) & $\%$ \\
\hline Usia ibu & & \\
$\quad$ Ideal & 8 & $80,0 \%$ \\
$\quad$ Berisiko & 2 & $20,0 \%$ \\
Paritas & & \\
$\quad$ Primi & 3 & $30,0 \%$ \\
$\quad$ Multi & 7 & $70,0 \%$ \\
Pendidikan ibu & & \\
$\quad$ Menengah & 3 & $30,0 \%$ \\
$\quad$ Rendah & 7 & $70,0 \%$ \\
Pekerjaan ibu & & \\
$\quad$ IRT & 9 & $90,0 \%$ \\
$\quad$ Honorer & 1 & $10,0 \%$ \\
\hline
\end{tabular}

Tabel I menunjukkan bahwa mayoritas usia ibu hamil yang mengikuti kegiatan adalah usia ideal yaitu 21-35 tahun sebanyak 8 orang dan sisanya usia berisiko yaitu $>35$ tahun. Usia menunjukkan hasil secara signfikan usia ibu >30 tahun dapat menyebabkan keterlambatan onset laktasi. Usia lebih tua memiliki faktor risiko intolerans kadar karbohidrat selama kehamilan, sehingga mengakibatkan peningkatan IMT pada saat kehamilan (Nommsen-Rivers et al., 2010). Sebagian besar paritas ibu dengan adalah multi sebanyak 7 orang $(70 \%)$. Ibu yang melahirkan >1 kali, menunjukkan pengeluaran ASI pada hari ke-4 setelah melahirkan lebih tinggi dibanding ibu melahirkan pertama kali (Rahardjo, 2006).

Pendidikan ibu didominan pada tingkat rendah yaitu hanya sampai tingkat SD dan SMP sederajat sebanyak 7 orang $(70 \%)$ dan 3 orang tingkat menengah $(30 \%)$. Mayoritas ibu hamil adalah bekerja sebagai IRT bertugas mengurus rumah, anak dan suami yaitu sebanyak 9 orang $(90 \%)$ sisanya sebagai honorer mengajar di sekolah dasar pada hari tertentu saja.

Pada keadaan-keadaan tertentu pijat laktasi dapat dilakukan untuk menstimulasi produksi ASI. Misalnya membantu proses induksi menyusui (untuk ibu adopsi/ibu angkat/belum pernah menyusui). Manfaat pijat laktasi adalah membantu relaksasi tubuh dan pikiran ibu, memperlancar sirkulasi darah, stimulasi hormon produksi dan pengaliran ASI dan mengkondisikan ibu dan bayi lebih menikmati proses menyusui (Dewi \& Aprilianti, 2018).

\section{KESIMPULAN}

Kegiatan pengabdian kepada masyarakat ini dihadiri oleh 10 orang ibu hamil yang terdaftar dan bertempat tinggal di wilayah Puskesmas Jekan Raya. Kegiatan ini direspon baik oleh bidan, kader, ibu hamil dan keluarganya. Diharapkan kegiatan penyuluhan tentang pijat laktasi pada ibu hamil dapat dijadikan sebagai program rutin dari puskesmas dan petugas kesehatan, sehingga dapat mendampingi dan menyiapkan ibu hamil dengan pengetahuan tentang ASI Eksklusif menjelang persalinan. 


\section{REFERENSI}

Aditya, M., Utama, W.T., Puspitasari, R.D., Nareswari, S. 2015. Peningkatan Pengetahuan Ibu Usia Reproduktif Melalui Penyuluhan Dan Simulasi Tentang Asi Eksklusif Untuk Meningkatkan Derajat Kesehatan Ibu Dan Anak Di Puskesmas Way Kandis Bandarlampung. JPM (Jurnal Pengabdian Masyarakat) Ruwa Jurai. 1(1):1-4. https://doi.org/10.23960/jpm.v1i1.1135

Aprilianti, C. 2018. Pijat Laktasi Dan Pijat Oksitosin Terhadap Onset Laktasi Di Kota Palangka Raya. JIDAN (Jurnal Ilmiah Bidan). 6(1):31-37.

Ariestanti, Y., Widayati, T. 2018. Peningkatan Pengetahuan Ibu Tentang ASI Eksklusif di Pondok Melati Bekasi. Jurnal Pelayanan dan Pengabdian Masyarakat (Pamas). 2(1):67-71.

Dewi, R.A., Aprilianti, C. 2018. Pijat pada Ibu Postpartum dengan Onset Laktasi. Jurnal Kesehatan. 9(3):376-381.

http://dx.doi.org/10.26630/jk.v9i3.1097

Dinas Kesehatan Kalimantan Tengah. 2017. Profil Kesehatan 2016 Provinsi Kalimantan Tengah. Palangka Raya: Dinas Kesehatan Kalimantan Tengah.

Fajar, N.A., Purnama, D.H., Destriatania, S., Ningsih, N. 2018. Hubungan Pemberian ASI Eksklusif dalam Prespektif Sosial Budaya di Kota Palembang. Jurnal Ilmu Kesehatan Masyarakat. 9(3):226-234. https://doi.org/10.26553/jikm.2018.9.3.226234

Fikawati, S., Syafiq, A. 2010. Study on Policy and Implementation of Exclusive and Early Initiation of Breastfeeding in Indonesia. Makara Journal of Health Research. 14(1):17-24. https://doi.org/10.7454/msk.v14i1.642

Kementerian Kesehatan Republik Indonesia. 2017. Profil Kesehatan Indonesia Tahun 2016. Jakarta: Kementerian Kesehatan Republik Indonesia.

Nommsen-Rivers, L.A., Chantry, C.J., Peerson, J.M., Cohen, R.J., Dewey, K.G. 2010. Delayed onset of lactogenesis among first-time mothers is related to maternal obesity and factors associated with ineffective breastfeeding. The American Journal of Clinical Nutrition. 92(3):574584. https://doi.org/10.3945/ajcn.2010.29192
Oktafirnanda, Y., Listiarini, U.D., Agustina, W. 2019. Pengaruh Implementasi Pijat Oksitosin Terhadap Pengeluaran Asi Pada Ibu Nifas Di Klinik "S" Simpang Marbau. Jurnal Bidan Komunitas. 2(3):144-152. https://doi.org/10.33085/jbk.v2i3.4453

Rahardjo, S. 2006. Faktor-faktor yang Berhubungan dengan Pemberian Asi Satu Jam Pertama Setelah Melahirkan. Kesmas: Jurnal Kesehatan Masyarakat Nasional $=$ Kesmas: National Public Health Journal. 1(1):11-17. http://dx.doi.org/10.21109/kesmas.v1i1.321

Saudia, B.E.P. 2019. Upaya Peningkatan Pengetahuan Dan Keterampilan Ibu Menyusui Dalam Pemberian Terapy Komplementer Massage Endorphin Dan Pijat Laktasi Di Kelurahan Dasan Cermen. Jurnal Pengabdian Masyarakat Sasambo.

1(1):47-51. http://dx.doi.org/10.32807/jpms.v1i1.479

Septiani, R., Martini, M., Andini, L.F. 2018. Efektivitas Pijat Oksitosin Dan Aromaterapi Clary Sage Terhadap Onset Laktasi. Jurnal Ilmiah Keperawatan Sai Betik. 14(2):211-214. http://dx.doi.org/10.26630/jkep.v14i2.1309 